\title{
VULNERABILIDADE DE JOVENS E ADOLESCENTES À INFECÇÃO POR HPV E AS CONDUTAS PREVENTIVAS DA ENFERMAGEM
}

\section{VULNERABILIDAD DE LOS JÓVENES Y ADOLESCENTES A LA INFECCIÓN POR HPV Y LA CONDUCTA PREVENTIVA DE ENFERMERÍA}

\author{
VULNERABILITY OF YOUNG AND ADOLESCENTS TO HPV INFECTION AND \\ NURSING PREVENTIVE CONDUCT
}

Daniel Aser Veloso COSTA ${ }^{1}$

Tayanne Rodrigues RIBEIRO ${ }^{2}$

RESUMO: Trata-se de uma revisão de literatura, utilizando diferentes bases de dados e descritores, "HPV", "adolescentes", “jovens" e "enfermagem", com objetivo de conhecer as principais causas de vulnerabilidades à infecção pelo HPV em jovens e adolescentes, bem como as ações da enfermagem que favorecem a prevenção de contaminação por este vírus. Foi possível evidenciar que a população jovem tem comportamentos sexuais de risco, os deixando vulneráveis à infecção por HPV, e isso sugere que o enfermeiro necessita estar apto para assistência integral e contínua aos jovens e adolescentes, identificando situações de risco, desenvolvendo ações educativas e preventivas juntamente com a família e comunidade, visando o melhoramento da saúde sexual e reprodutiva desta faixa etária.

PALAVRAS-CHAVE: Adolescentes. HPV. Jovens. Enfermagem. Prevenção de doenças.

RESUMEN: Esta es una revisión de la literatura, utilizando diferentes bases de datos y descriptores "HPV", "adolescentes", "jóvenes" y "enfermería", para conocer las principales causas de vulnerabilidad a la infección por HPV en jóvenes y adolescentes, así como acciones de enfermería que favorecen la prevención de la contaminación por este virus. Se pudo demostrar que la población joven tiene comportamientos sexuales de riesgo, lo que los deja vulnerables a la infección por VPH, y esto sugiere que la enfermera debe poder brindar atención integral y continua a Jóvenes y adolescentes, identificando situaciones de riesgo, desarrollando acciones educativas y preventivas junto a la familia y la comunidad, con el objetivo de mejorar la salud sexual y reproductiva de este grupo de edad.

PALABRAS CLAVE: Adolescentes. HPV. Jovenes. Enfermería. Prevención de enfermedades.

ABSTRACT: This is a review of the literature, using different databases and descriptors, "HPV", "teenagers", "young" and "nursing", in order to know the main causes of vulnerability to HPV infection in young people and adolescents as well as the nursing actions that favor the prevention of contamination by this virus. It was possible to show that the young population

${ }^{1}$ Faculdade Pitágoras - (FAP), São Luís - MA - Brasil. Docente do Departamento de Enfermagem. ORCID: https://orcid.org/0000-0001-8924-0032. E-mail: danielaser@gmail.com

${ }^{2}$ Faculdade Pitágoras - (FAP), São Luís - MA - Brasil. Discente de enfermagem. ORCID: https://orcid.org/00000001-8195-4524. E-mail: tayanneribeiro@gmail.com 
has riskier sexual behaviors, leaving them vulnerable to HPV infection, and this suggests that the nurse needs to be able to provide comprehensive and continuous care to the young people and adolescents, identifying risk situations, developing educational and preventive actions together with the family and community, aiming at improving the sexual and reproductive health of this age group.

KEYWORDS: Adolescents. HPV. Young. Nursing. Prevention of diseases.

\section{Introdução}

A infecção pelo papilomavírus humano (HPV) está entre os problemas de saúde pública mais comuns no Brasil e no mundo, com grande prevalência na população jovem. O comportamento sexual de jovens e adolescentes é um tema que tem grande relevância no âmbito da saúde. O início precoce da vida sexual, a não existência de parceiros sexuais fixos, e a utilização de álcool e outras drogas fazem com que os jovens sejam considerados como um grupo vulnerável às infecções sexualmente transmissíveis em especial a infecção pelo HPV (BRASIL, 2017).

Analisa-se a proposta deste trabalho a partir da população jovem mais suscetível à infecção por HPV. Compreende-se que é imprescindível uma investigação na área da enfermagem para que se apontem causas e ações preventivas no combate resolutivo a este tipo de demanda, tendo em vista que nessa fase pode ocorrer o início da vida sexual desprotegida, propiciando alta vulnerabilidade à problemas de cunho sexual e reprodutivo (RODRIGUES; SOUSA, 2015).

A falta de informações adequadas a respeito do Papiloma Vírus Humano e a não utilização de preservativos os levam a adquirir este vírus, que é o principal causador do câncer de colo de útero, além de sua associação com outros tipos de cânceres como o de pênis, de orofaringe e, até mesmo, de câncer reto-anal. Diante disso é necessário entender porque jovens e adolescentes se tornam tão vulneráveis à infecção por HPV? Que tipos de ações a enfermagem pode realizar para auxiliar na prevenção dessa infecção?

Nesse sentido, foi realizada uma pesquisa do tipo revisão de literatura, sendo utilizados artigos científicos em língua portuguesa, manuais, livros, revistas, jornais e publicações do Ministério da Saúde, tendo como base as publicações dos últimos 10 anos, que trataram dos aspectos do HPV relacionados aos jovens e adolescentes e ainda os meios de prevenção deste vírus, por parte da enfermagem. Sendo a busca do material através de consulta eletrônica nas bases de dados LILACS (Literatura Latino-Americana e do Caribe em Ciências da Saúde), 
SciELO (Scientific Eletronic Library Online), BVS (Biblioteca Virtual em Saúde) e BDENF (Base de dados de Enfermagem).

O presente trabalho tem como foco, portanto, estudar sobre o Papilomavírus humano e o quão suscetíveis jovens e adolescentes se tornam frente à essa infecção, ainda busca-se constatar, por meio dos dados fornecidos pela literatura disponível, se os mesmos sabem o que é o vírus bem como a forma de preveni-lo, além disso evidenciar como a enfermagem pode contribuir, preventivamente, de modo a reduzir a quantidade de infectados por este vírus na população jovem, visando o melhoramento da saúde sexual e reprodutiva desta faixa etária.

\section{Metodologia}

Este estudo traz uma revisão da literatura, de caráter descritivo e qualitativo, fundamentado em pesquisas acadêmicas através de materiais já elaborados, constituído de artigos científicos em língua portuguesa, manuais, livros, revistas, jornais e publicações do Ministério da Saúde, tendo como base as publicações dos últimos 10 anos, sendo a busca do material através de consulta eletrônica nas bases de dados LILACS (Literatura LatinoAmericana e do Caribe em Ciências da Saúde), SciELO (Scientific Eletronic Library Online), BVS (Biblioteca Virtual em Saúde) e BDENF (Base de dados de Enfermagem). Estão sendo utilizadas as seguintes palavras chaves para a busca de artigos nas bases de dados: "HPV", “ADOLESCENTES”, “JOVENS”, "ENFERMAGEM”.

A partir da busca realizada, será feita leitura e tradução do material, bem como a análise dos mesmos. Para esta análise serão seguidos alguns passos, como a seleção do material, considerando critério de inclusão os textos que tratarem dos aspectos do HPV relacionados a jovens e adolescentes e ainda os meios de prevenção deste vírus que podem ser auxiliados pela enfermagem. Sendo excluídos aqueles que não responderem aos critérios de inclusão.

Desta forma foram realizadas as seguintes etapas: pesquisa bibliográfica referente ao conteúdo analisado; levantamento das informações e coletas de dados através de pesquisas em obras publicadas; análise e interpretação dos dados coletados.

\section{Principais características do vírus HPV}

O HPV é uma sigla inglesa Human papillomavirus (Papiloma Vírus Humano), é um vírus epiteliotrópico que causa infecções na pele e nas mucosas (LETO et al., 2011). Este vírus “induz infecções predominantemente no trato ano genital". Aproximadamente $30 \%$ da 
população sexualmente ativa está infectada por ele (FRANCO, 2015, p. 284). O Vírus do papiloma humano (HPV) foi o primeiro vírus oncogênico a ser transmitido experimentalmente de um hospedeiro para o outro (SANTOS; ROMANOS; WIGG, 2008, p. 455).

Atualmente, a infecção por HPV é a doença sexualmente transmissível mais frequente, ou seja, é a principal infecção viral transmitida pelo sexo. Segundo o Ministério da Saúde (2017), a principal forma de transmissão do HPV é por via sexual (oral-genital e genitalgenital), podendo mais raramente ser transmitido também durante o parto ou ainda, por determinados objetos. O Instituto Nacional do Câncer (INCA, 2012) aponta o HPV como o precursor do câncer de colo de útero e o responsabiliza por $90 \%$ dos cânceres cervicais. "A infecção pelo vírus do Papiloma Humano (HPV) se caracteriza como uma doença sexualmente transmissível com alta prevalência no mundo" (RODRIGUES; SOUSA, 2015, p. 2). Segundo o Instituto do HPV em torno do mundo, há em volta de 600 milhões de pessoas infectadas. Em todo o planeta, cerca de $10 \%$ das mulheres têm HPV. Entre elas, de $30 \%$ a $50 \%$ são jovens menores de 25 anos. Em relação ao sexo feminino, o epitélio uterino é menos resistente do que o epitélio peniano no sexo masculino e, durante o ato sexual, podem acontecer lesões no epitélio vaginal, deixando o sexo feminino mais suscetível à infecção por HPV (RODRIGUES; SOUSA, 2015).

Porém, assim como no sexo feminino, os adolescentes e jovens do sexo masculino também estão expostos à infecção por HPV. A frequência de verrugas genitais é maior no sexo masculino do que no sexo feminino, predominando na faixa etária de jovens de 20 a 24 anos. Sendo que a infecção por HPV no sexo masculino está associada ao desenvolvimento de câncer de ânus, pênis, língua, boca e garganta, já no feminino está mais comumente associado ao câncer de colo de útero. No Brasil estima-se que 9 a 10 milhões de pessoas sejam portadoras do vírus e que se registrem 700 mil novos casos a cada ano. Entre a população sexualmente ativa, estima-se que $80 \%$ vão contrair HPV durante a vida, causando doenças significativas. Espera-se o aparecimento de 17.540 novos casos de HPV, sendo 780 localizados no estado do Maranhão. Segundo a Associação Hospitalar Moinhos de Vento, a prevalência de HPV em jovens e adolescentes de São Luís (MA) é de 59,1 \% (BRASIL, 2017).

\section{Vulnerabilidades de jovens e adolescentes à infecção por HPV}

Existem várias definições para o ser adolescente/jovem, segundo o Estatuto da Criança e do Adolescente (ECA, 2018), são considerados adolescentes os cidadãos com idade entre 12 e 18 anos. Alguns estudiosos consideram que a juventude vem logo depois da adolescência, 
mais precisamente entre 19 e 29 anos. O estatuto da juventude afirma que são considerados jovens aqueles com idade entre 15 e 29 anos. Mas para o IBGE (Instituto Brasileiro de Geografia e Estatística, 2010) órgão oficial de estatísticas, jovem deve ser definido como indivíduo dos 15 aos 24 anos. Porém, classificar esta faixa etária desta forma é apenas quantificá-la para produzir programas de saúde (BRASIL, 2016).

A adolescência pode ser compreendida como um processo biologicamente fundamental, que ocorre nos jovens e adolescentes entre os 10 e 19 anos de idade. É um período no qual acontecem várias mudanças, podendo ser de ordem fisiológica, controlada por hormônios que provocam o surgimento de características sexuais secundárias, ou por fatores psicológicos (BRASIL, 2016).

No princípio da adolescência/juventude, as transformações biológicas e as alterações na personalidade ocorrem simultaneamente, fazendo com que o corpo adquira uma nova forma e modificando concomitantemente a imagem mental (SILVA; CRUZ; COELHO 2008). As mudanças propícias desta fase, também conhecida como puberdade, ocorrem de formas universais e bem notórias, pois modificam a criança dando-lhe altura, forma física e sexualidade adulta (AYRES, 2012).

Por ser uma fase de transição entre a infância e a vida adulta, a adolescência é caracterizada por um período de dúvidas e sentimentos conflituosos em relação à vivência da sexualidade. Os adolescentes integram um grupo que necessita de atenção diferenciada pois, em sua maioria, iniciam a vida sexual quando ainda apresentam baixo conhecimento sobre as doenças sexualmente transmissíveis (DST's) e tem compreensão errônea sobre o risco pessoal de adquirir essas doenças, levando em conta que os mesmos não fazem uso das medidas efetivas de proteção (JARDIM et al., 2013).

Segundo Paiva (2008), a sexualidade por jovens e adolescentes está sendo vivida de forma cada vez mais livre nos dias atuais, porém, embora haja liberdade e estímulo sexual, existem divergências nas experiências entres estes, em que na maioria das vezes é iniciado o comportamento sexual de risco, apresentando negligência quanto à prevenção de infecções sexualmente transmissíveis (IST's). Os jovens e adolescentes, na maioria das vezes, não estão preparados para assumir tal responsabilidade, devido à imaturidade, inexperiência e falta de acesso a informações, seja no ambiente escolar ou familiar, características próprias desta faixa etária (JARDIM et al., 2013).

De acordo com Cirino, Nichiata e Borges (2010) os jovens e adolescentes constituem uma população de alta suscetibilidade para infecções sexualmente transmissíveis, tendo em vista que, o início da vida sexual os deixa mais próximos de problemas de saúde da esfera 
sexual e reprodutiva. As infecções sexualmente transmissíveis são predominantes na adolescência/juventude e facilitadoras da contaminação por várias doenças sexualmente transmissíveis, dentre elas o HPV.

Diante do exposto, existem vários fatores de risco que levam à infecção por HPV nos jovens e adolescentes: o início da vida sexual precoce; a variação de parceiros; a não utilização de preservativos e o uso de drogas ilícitas; tabagismo e o uso anticoncepcionais orais, que são favoráveis a infecções sexualmente transmissíveis, em especial HPV (RODRIGUES; SOUSA, 2015).

\section{O início da vida sexual precoce e a promiscuidade como fator de risco à infecção por HPV}

A coitarca inclui-se em um conjunto de fatores e experiências que formam parte da identidade social e sexual dos indivíduos, para os jovens a primeira relação sexual é um acontecimento que além de marcar o processo da passagem a vida adulta é o início de novas possibilidades de uso do corpo com outros indivíduos (GONÇALVES et al., 2009).

Consoante com Silva et al. (2015), o princípio da prática sexual é um momento muito importante na vida dos jovens e adolescentes. Porém, embora esta prática lhes permita entrar em um mundo de novas descobertas, pode também os inserir em um grupo de alta vulnerabilidade às infecções sexualmente transmissíveis inclusive o HPV. É geralmente na fase da adolescência/juventude em que os indivíduos iniciam suas práticas sexuais.

Segundo Macêdo et al., (2015), embora jovens e adolescentes estejam preparados fisiologicamente, a iniciação sexual precoce ligado a fatores biológicos, psíquicos e sociais, tendem a aumentar a vulnerabilidade à ISTs, fazendo com que os jovens e adolescentes se tornem alvos preferenciais para à infecção por HPV, portanto, quanto mais precoce o início da atividade sexual, maior o risco de infecção.

De acordo com Silva et al., (2015) com o início mais precoce da atividade sexual dos jovens e adolescentes, as chances de aumentar a promiscuidade são maiores, pois certamente terão um período maior de atividade sexual e, consequentemente, mais parceiros sexuais até que obtenham relacionamentos estáveis, monogâmicos e duradouros. Portanto, o Papilomavírus humano é constantemente encontrado entre os jovens e adolescentes pelo fato de as relações sexuais nessa faixa etária ocorrerem com um grande número de parceiros e em sua maioria desprotegida, o que influencia positivamente a ocorrência da infecção por HPV (MACÊDO et al., 2015). 
Para Carrilo e Goldenberg (2014), ter múltiplos parceiros sexuais, serem profissionais do sexo, bem como clientes dos mesmos, são fatores de risco relevantes que deixam os jovens e adolescentes altamente vulneráveis à presença de infecções sexualmente transmissíveis, podendo implicar no aumento de 25 a 36 vezes o risco de contágio pelo HPV.

\section{Falta de prevenção e o uso de contraceptivos favoráveis à infecção por HPV}

Acredita-se que a precocidade nas relações sexuais na adolescência acompanhada de falhas e/ou inconsistência, em conjunto com as altas taxas de práticas sexuais com diferentes parceiros, torna os jovens e adolescentes favoráveis às infecções sexualmente transmissíveis, principalmente o HPV. O preservativo ainda não é utilizado por todos os jovens e nem em todas as relações sexuais, tendo em vista que, seu uso depende dentre outros motivos, "do envolvimento afetivo do momento, questões financeiras e de acesso aos métodos, bem como o grau de liberdade e autonomia alcançadas nesta faixa etária" (LIMA et al., 2014).

Entende-se com o estudo de Torres et al. (2013), que não só o preço seja impedimento para adquirir o preservativo, mas a vergonha é um fator importante de impedimento ao acesso do mesmo. Nota-se que as campanhas de distribuição gratuitas de preservativos, da maneira como são feitas, não funcionam corretamente com os adolescentes, por serem monolíticas e não levarem em conta as especificidades e as dificuldades ligadas a cada sexo e a cada classe, sendo assim, são feitas para um adolescente "unissex, tamanho único”.

Os jovens e adolescentes propendem a não utilizar preservativo quando iniciam a prática sexual precocemente, entre outras causas e motivos associados ao uso e não uso, que tendem a ser bem diferentes em cada situação, o uso do preservativo é determinado não apenas por fatores individuais, mas também socioculturais. E para que o preservativo funcione para evitar o HPV, é necessário que este seja utilizado em todas as relações sexuais, pois basta uma única relação para que ocorra a transmissão de doenças sexualmente transmissíveis (BRASIL, 2017).

A não utilização de preservativos, bem como a má higienização que inclui: contaminação pelos dedos, compartilhamentos de brinquedos sexuais e antecedentes de infecções sexualmente transmissíveis, predispõem esse grupo à contaminação e o desenvolvimento da infecção por HPV. Além de que a confiança em seus(suas) parceiros(as), principalmente em relacionamentos estáveis, serve de justificativa para o não uso de preservativo, que também é um fator de risco para a contaminação pelo Papilomavírus humano (CARRILO; GOLDENBERG, 2014). 
O uso de contraceptivos é outro fator de risco que deixa as adolescentes vulneráveis às infecções sexualmente transmissíveis, em especial o HPV. Não só pelo fato de que o anticoncepcional evitará uma gravidez indesejada, fazendo com que as mesmas não façam questão do preservativo, mas também por ser um fator de relevante etiopatogenia, principalmente se a utilização do mesmo acontecer antes do completo desenvolvimento do trato genital feminino, ou seja, antes dos 17 anos (LUSTOSA et al., 2016).

Em populações em que a quantidade de parceiras entre os homens é elevada, e a prostituição é habitual, o risco de as adolescentes adquirirem HPV depende mais do comportamento sexual dos seus parceiros do que delas mesmo (CARRILO; GOLDENBERG, 2014). Acerca da contaminação do HPV no sexo feminino, Lustosa et al. (2016) afirma que:

As adolescentes são mais vulneráveis às infecções por HPV devido à exposição da zona de transformação da cérvice (Junção Escamocolunar, JEC) durante a adolescência, o que não ocorre na vida adulta. Neste local, as células colunares sofrem metaplasia escamosa que o torna mais propenso a infecções por agentes patogênicos de transmissão sexual, como o HPV. Sendo também o local de origem da maioria das lesões percursoras e carcinomas cervicais. Além deste, durante a adolescência há uma menor produção de muco cervical, sendo este responsável por formar uma espécie de barreira protetora contra agentes infecciosos, que associado a uma área maior de ectopia torna-se um fator contribuinte para a infecção pelo HPV (p. 345).

Tanto os jovens e adolescentes do sexo masculino quanto do sexo feminino, infectados pelo HPV, são na maioria das vezes portadores do vírus, mas desconhecem, principalmente, quando não possuem sintomas visíveis, podendo transmitir o vírus aos seus parceiros sexuais. No entanto, a evolução e a manifestação são diferentes em ambos os sexos. Isto ocorre, porque há diferenças anatômicas e hormonais. O órgão genital da mulher permite maior desenvolvimento e multiplicação do HPV, podendo ocorrer complicações mais severas, como lesões, que, se não tratadas, podem evoluir para o câncer de colo de útero, apesar de que no sexo masculino existem várias formas de câncer que também podem lhe acometer, como o câncer de pênis, por isso, há necessidade da utilização do preservativo, podendo ser feminino ou masculino (BRASIL, 2017).

\section{O uso de drogas e o HPV}

De acordo com os estudos de Campo-Aria, Ceballo e Herazo (2010) os jovens e adolescentes utilizam álcool e drogas como relaxamento, diversão, quebra da timidez, para conseguirem se expressar melhor, e também como meio de "fuga da realidade", o que os deixa expostos a inúmeros riscos, principalmente às relações sexuais casuais que na maioria das vezes 
ocorrem desprotegidas, evidenciando-se assim, a associação entre a maneira comportamental de risco para a saúde sexual e reprodutiva ao uso de drogas lícitas e ilícitas na população de jovens e adolescentes.

Para Pires et al. (2010), esta é a maneira do jovem/adolescente demonstrar que nada acontecerá com ele, "em relação ao uso de drogas, consideram que não são tão perigosas, que podem afastar-se delas em qualquer momento, tendo total controle da situação", fazendo com que estes tenham uma menor percepção do risco, aumentando o uso. Isso, por outro lado, insere o adolescente usuário de drogas num grupo de alta vulnerabilidade

Entre as doenças relacionadas ao uso de drogas destacam-se, especialmente, as infecciosas, em especial o HPV, podendo ser decorrente do compartilhamento de agulhas e seringas ou ainda de relações sexuais sem uso de preservativo ainda sob o efeito de substâncias químicas, estando também atrelado, principalmente, a usuários de baixa escolaridade e baixo poder aquisitivo. Sendo assim, o uso de drogas pode ainda estar relacionado a outros fatores de risco para a saúde dos jovens e adolescentes, como um maior envolvimento em atividades ilegais, maior envolvimento em prostituição, por exemplo, fazer sexo em troca de drogas (DUAILIBI; RIBEIRO; LARANJEIRA, 2008).

\section{Condutas preventivas da enfermagem frente infecção por HPV em jovens e adolescentes}

O enfermeiro atua como educador em saúde e suas atuações podem contribuir para a redução de possíveis agravos do HPV em jovens e adolescentes. O enfermeiro é um profissional capacitado para realizar ações de educação em saúde, sobre a infecção pelo vírus HPV e outras infecções sexualmente transmissíveis, conscientizando o indivíduo do sexo seguro, uso do preservativo do início ao fim do ato sexual oral, anal e vaginal. Orientar para que os adolescentes diminuam o número de parceiros, pois quanto mais parceiros sexuais, maior o risco da infecção pelo HPV. O enfermeiro é um dos profissionais que tem mais proximidade com os indivíduos, portanto, é um profissional que tem um papel de extrema importância na saúde preventiva, utilizando de sua familiaridade e conhecimentos para disseminar informações pertinentes aos jovens e adolescentes, tornando-se propagador de normas preventivas para que estes tenham uma vida saudável (DUAVY et al., 2017).

Assim, tem-se no Enfermeiro da Estratégia de Saúde da Família um novo modelo de assistência à saúde, sendo o profissional que tem grande relevância, visto que é de sua responsabilidade, entre outras, a consulta ginecológica, bem como a realização de atividades educativas que visam o autocuidado e a prevenção de agravos. Portanto, é de competência da 
enfermagem alertar os jovens e adolescentes acerca dos comportamentos de saúde sexual, fatores de risco após a infecção por HPV - associados ao risco de desenvolvimento de câncer de colo de útero ou de pênis, por exemplo - e métodos de rastreamento de detecção precoce da doença (BRASIL, 2016).

Por tanto, ao realizar atividade educativa individualmente, ou seja, como parte de aconselhamento, necessita de planejamento levando em consideração a capacidade de compreensão do jovem e/ou adolescente, assim como o nível educacional, histórico pessoal e antecedentes familiares, de forma holística e específica de cada paciente, respeitando suas crenças e hábitos culturais. Com isso, os profissionais precisam ser conscientes das diretrizes dos programas que envolvem os jovens e adolescentes, promovendo ações sobre higiene e estilo de vida saudável, o que torna o enfermeiro fundamental na prevenção do HPV (QUINTELLA; ZANON, 2012).

Os enfermeiros, por serem profissionais que habitualmente tem interação próxima e direta com os pacientes, podem ser o primeiro contato com estes. Na consulta, o jovem e/ou adolescente e sua família podem ser avaliados, para identificação de fatores que aumentam o risco de infecção por HPV, e para direcionamento à intervenções que podem ser realizadas pela enfermagem ou por meio de encaminhamento a outros profissionais da equipe multidisciplinar (FERREIRA; ROCHA, 2014).

Em seus estudos, Cianciarullo (2011), afirma que a consulta de enfermagem deve instaurar uma relação de confiança entre o profissional e o cliente, assegurando o caráter sigiloso do atendimento, elevando a autoestima do mesmo, promovendo o diálogo e, por conseguinte, a verbalização dos sentimentos e concepções, bem com o conhecimento do próprio corpo, enfatizando o autocuidado e capacitando-o para percepção de prováveis situações de risco vivenciado por ele.

Assim, de acordo com Duavy et al. (2017), “durante a consulta o enfermeiro deve identificar aspectos da história de vida e saúde do paciente, além de outras informações como antecedentes pessoais e familiares do mesmo". Entretanto, os autores evidenciam que não só os aspectos teórico-científicos devem ser levados em conta, podendo causar prejuízo psicoafetivos na relação enfermeiro-cliente.

Sobre esta relação mais profunda do enfermeiro com a população, Duavy et al. (2017), afirmam que instaura circunstâncias para redefinir de forma crítica a prática em diversos serviços de saúde, visando um atendimento que atenda as demandas dos indivíduos. Dessa forma, Quintella e Zanon (2012) afirmam que "vai se configurando no Brasil, uma postura entre 
os profissionais de saúde e a população, voltada para a gestação de novos conhecimentos e de novas formas de organização social”.

O enfermeiro exerce uma função, extremamente, crucial nas ações de prevenção de infecção por HPV, levando em consideração que as práticas de enfermagem estão sofrendo constantes mudanças, nas quais há maior autonomia profissional em especial da enfermagem, liberdade e desenvolvimento de competências dos enfermeiros, modernizando as maneiras de assistência e a necessidade de trabalhos em harmonia com a equipe multidisciplinar. O que leva a uma consulta otimizada e resulta num melhor atendimento (QUINTELLA; ZANON 2012).

De acordo com o Ministério da Saúde (2009), o enfermeiro é considerado o principal profissional atuante no programa de saúde do adolescente, direcionando o seu atendimento no acompanhamento do jovem e/ou adolescente de forma holística, levando em consideração os princípios e diretrizes do Sistema Único de Saúde (SUS). Nesse sentido, a enfermagem deve ponderar para a técnica social vinculada à comunidade, evidenciando que o principal objetivo do enfermeiro em relação ao jovem/adolescente é atuar na promoção de saúde e na prevenção de doenças - em especial a infecção por HPV - neste grupo tão vulnerável, ofertando aos jovens e adolescentes atendimentos interdisciplinares, em conjunto com a família e sociedade (BRASIL, 2009).

Os profissionais de enfermagem têm evidenciado, de modo crescente, às atividades de promoção da saúde e de prevenção de doenças como formas importantes de assistência à saúde. Estas atividades ajudam os jovens e adolescentes a manterem-se saudáveis, e melhorar seu nível de bem-estar atual ou futuro. As atividades de prevenção de doenças, principalmente a infecção por HPV, estão direcionadas à proteção do cliente contra as ameaças reais ou potenciais à saúde. Ambas são orientadas para o futuro e divergem entre motivações e objetivos. Partindo do pressuposto, de que é na adolescência/juventude o momento em que aflora à busca da identidade sexual, transformação do corpo e experiências sexuais, faz-se necessário pensar na questão da sexualidade, que pode ser entendida como um elemento importante na formação da identidade do jovem e/ou adolescente, mediante descoberta da imagem corporal de si e do próximo e das relações estabelecidas. Além disso, apesar da sexualidade como prática normal do dia a dia, esta traz grande complexidade no que diz respeito aos aspectos cognitivos, sensoriais e cultuais relacionados (LIMA et al., 2014).

Diante do exposto, cabe aos enfermeiros, em vista das habilidades e competências da profissão, se disporem a ouvir os jovens e adolescentes, ganhar a confiança dos mesmos, garantir a confidencialidade e trocar conhecimentos. Portanto, a discussão sobre essa temática, não deve permear somente nos aspectos fisiológicos do organismo humano, mas também 
agregar valores culturais e sociais, fazendo com que jovens e adolescentes tenham consciência de suas próprias atitudes, tendências e sentimentos (LIMA et al., 2014).

Os enfermeiros devem ser os cuidadores e promotores da saúde, devendo aproximar-se da realidade dos jovens e adolescentes para que conheçam os problemas que os afligem e possam contribuam na a elaboração de políticas públicas, bem como programas de prevenção e tratamento, visando sempre o aperfeiçoamento de uma boa qualidade de vida. Nesse contexto, lidar com a saúde do jovem e/ou adolescente na prevenção de riscos e agravos, mostra-se eficiente com a utilização da educação em saúde, por meio de oficinas, palestras, rodas de conversa e encontros. Todavia, é necessário que se tenha conhecimento das vulnerabilidades e riscos aos quais estes jovens e adolescentes estão expostos. Para isso, necessita-se que o enfermeiro conheça sua área de atuação, bem como o trabalho de sua equipe e, principalmente, conhecer os adolescentes e jovens. Pois não se pode prestar serviços assistenciais aos jovens e adolescentes sem conhecê-los. É imprescindível que a enfermagem conheça essa população, para que ocorra uma melhoria na qualidade da assistência aos jovens e adolescentes (LIMA et al., 2014).

Consoante, Ferreira et al. (2015), diz que "a vacina é importante instrumento de prevenção do câncer de colo útero em todo o mundo. É um produto recombinante que estimula a resposta humoral, capaz de induzir elevados títulos de anticorpos, superiores a infecção natural”. Em 2014, o Ministério da Saúde incluiu a vacina contra o HPV no Calendário Nacional de Vacinação. Ela é fornecida gratuitamente, pelo Sistema Único de Saúde (SUS), a meninas de 11 a 13 anos. Porém, a partir de 2015 foi estabelecido que serão vacinadas meninas de 09 a 14 anos e meninos de 11 a 14 anos (INSTITUTO ONCOGUIA, 2014). A respeito das vacinas profiláticas de HPV, Ferreira et al. afirmam que:

São compostas por VLPs (Vírus-Like Particles), estruturas semelhantes ao capsídeo viral, mas não possuem DNA viral, o que proporciona segurança à vacina, já que não é possível a replicação. As vacinas profiláticas já aprovadas pela ANVISA e disponíveis no mercado são: a bivalente, Cervarix® (GSK), que protege contra os tipos virais 16 e 18 e a quadrivalente, Gardasil ${ }^{\circledR}$ (MSD), que protege contra os tipos virais $6,11,16$ e 18 . As vacinas são fabricadas utilizando a mesma tecnologia, mas com pequenas diferenças no que se refere ao organismo geneticamente modificado, escolha do adjuvante, posologia e indicação. Ambas se apresentaram seguras e eficazes para os fins destinados. Apresentam proteção cruzada parcial e efêmera a outros tipos de HPV não presentes nas vacinas. Esses tipos são 31, 33, 35, 39, 45, 51, 52, 58, 59, 68. Isso se deve à similaridade genética entre alguns tipos de HPV. A campanha de vacinação contra o HPV no Brasil teve início em março de 2014. O público alvo dessa campanha são as meninas entre 9 e 13 anos. O esquema de vacinação adotado pelo Ministério da Saúde é chamado de "estendido" e composto por três doses. A vacina utilizada na campanha brasileira é a 
quadrivalente (Gardasil®) recomendada pela Organização Mundial da Saúde (FERREIRA et al., p. 02, 2015).

A infecção pelo Papilomavírus humano tem papel relevante no desenvolvimento do câncer do colo do útero. Estudos demonstram que o vírus está presente em mais de $90 \%$ dos casos de câncer cervical. A prevenção pode ser feita através do exame preventivo, que é o principal método e mais abrangentemente utilizado para rastreamento do câncer do colo do útero, também conhecido por teste de Papanicolau (BRASIL, 2017).

De acordo com a OMS, mulheres sexualmente ativas devem realizar o exame preventivo no mínimo uma vez ao ano, tendo em vista que a prioridade da coleta seja de cunho preventivo. Embora a realidade nacional seja divergente da recomendada, tendo em vista que muitas mulheres ainda são resistentes ao exame devido à falta de orientação, pudor, fatores históricoculturais dentre outros. É desejável que 48 horas antes da coleta do exame a mulher não realize duchas ou utilize cremes vaginais, nem mantenha relações sexuais, pois esses fatores podem causar alterações no resultado dos exames. Marques e Ramos p. 56 (2017), acerca do exame citopatológico, afirmam que:

O Enfermeiro é responsável pela assistência integral à saúde da mulher que deve abranger os seguintes conjuntos de ações: Promoção, prevenção, diagnóstico, tratamento e reabilitação. É responsável pelo controle dos fatores de risco, realização da consulta ginecológica e da coleta de exame de Papanicolau nas Unidades Básicas de Saúde, bem como incentivar o aumento da demanda de prevenção. Prestar assistência técnica satisfatória, orientando a mulher durante a consulta acerca do que será realizado no momento da coleta, a fim de garantir segurança e maior conforto no exame preventivo. É papel do Enfermeiro realizar atenção domiciliar quando necessário, supervisionar e coordenar a equipe da Unidade Básica de Saúde. Dar suporte a equipe da unidade é de extrema importância, através de reuniões, grupos de estudos, educação em saúde, fazendo assim com que a equipe seja coesa em relação a captação e orientação dessas mulheres (MARQUES; RAMOS, p. $56,2017)$.

Cruz e Jardim (2013), ressaltam que “os profissionais de saúde são vistos como a última fonte de conhecimento das adolescentes sobre este exame preventivo" e, acrescentam, que estes devem trabalhar não só na área da instituição de saúde, mas também em fazer parcerias com ações de prevenção e promoção à saúde na comunidade, estabelecendo contato com as jovens e adolescentes em outros ambientes como a escola, entre outros. É mencionado pelas autoras que "na intenção de conscientizar as adolescentes de sua participação na promoção da saúde, vale reafirmar a responsabilidade do enfermeiro nas ações educativas realizadas em sua prática profissional”, como no atendimento individual de enfermagem e nas visitas domiciliares que 
possibilitam conhecer ainda melhor a situação de vida do adolescente e de sua família, fortalecendo o vínculo entre este e o enfermeiro.

\section{Considerações finais}

A infecção pelo Papilomavírus humano (HPV), infecta dezenas de jovens e adolescentes anualmente, sendo preocupante, visto que, muitos deles desconhecem a doença, principalmente por ser um vírus assintomático, onde os portadores nesta faixa etária desconhecem que possuem o vírus, porém, disseminam o mesmo. Na maioria dos casos, esta infecção apresenta-se em forma latente e não há surgimento de lesões, o que faz aumentar o número de jovens e adolescentes contaminados.

Esse grupo se torna suscetível à infecção por HPV, por não ter conhecimento adequado a respeito do vírus e pelas práticas de vida e sexuais de risco, principalmente pelo início da atividade sexual precoce (quanto mais precoce maior o risco de infecção), abstenção do uso de preservativo e alta atividade sexual, além do uso de contraceptivos e ainda utilização de álcool e outras drogas. Dessa forma, conclui-se que viver a adolescência e/ou juventude com HPV, abrange silêncio, segredos, inquietações, busca pela normalidade, constatação nas diferenças, dúvidas em relação ao vírus e ainda adesão ao tratamento.

Portanto, deve-se atentar para urgência de implantação de ações preventivas por parte da enfermagem que investiguem percepções, dificuldades e necessidades específicas para cada demanda. O enfermeiro deve estar atento à qualidade dos cuidados a serem prestados, despindose de quaisquer formas de preconceitos e discriminação, focando na promoção e prevenção do Papilomavírus humano, com ações que devam estar voltadas para mobilização dos jovens e adolescentes, visando a prática do autocuidado, através de atividades educativas e preventivas.

Faz-se necessária a adesão de estratégias por parte dos profissionais de saúde, principalmente o enfermeiro, para atuar de maneira a facilitar a aderência dos jovens e adolescentes aos serviços de saúde, visando à prevenção da infecção por HPV, tendo uma atuação diferenciada, de forma holística, respeitando o jovem e/ou o adolescente em sua individualidade, privacidade, confidencialidade e direito de se inteirar sobre a doença e os fatores que a envolvem e principalmente sobre sua saúde. Sugere-se a realização de atividades em conjunto com os jovens e adolescentes, profissionais de saúde, família e comunidade. Fica evidente a importância do enfermeiro na consulta de enfermagem, conscientizando sobre a prevenção do HPV, através de exames, reforçando o uso de preservativos e vacinas profiláticas. 


\section{REFERÊNCIAS}

AYRES, J. R.; PAIVA V.; BUCHALLA C. M., Vulnerabilidade e Direitos Humanos Prevenção e Promoção da Saúde - Livro I - Da Doença à Cidadania. Curitiba: Juruá Editora, 31 ago., 320 p., 2012.

BRASIL. Decreto Lei n ${ }^{\circ} 12.852$, de 5 de agosto de 2013. Institui o Estatuto da Juventude e dispõe sobre os direitos dos jovens, os princípios e diretrizes das políticas públicas de juventude e o Sistema Nacional de Juventude - SINAJUVE. Diário Oficial da União, Brasília, DF, 6 ago. 2013. Disponível em: http://www.planalto.gov.br/CCIVIL_03/_Ato20112014/2013/Lei/L12852.htm. Acesso em: 20 nov. 2019.

BRASIL. Ministério da Saúde. Estudo epidemiológico sobre a prevalência nacional de infecção pelo HPV (POP-Brasil): Resultados preliminares. Associação Hospitalar Moinhos de Vento, Porto Alegre. 2017. 119 p.

BRASIL. Ministério da Saúde. Guia Prático Sobre HPV. 2017. 45 p.

CAMPO-ARIAS, A.; CEBALLO, G. A.; HERAZO, E. Prevalência do padrão de comportamento de risco para a saúde sexual e reprodutiva em estudantes adolescentes. Rev. Latino-Am. Enfermagem, Colômbia, v. 12, n. 2, mar./abr. 2010.

CIRINO, M.; NICHIATA, L.; BORGES, A. Conhecimento, atitude e práticas na prevenção do câncer de colo uterino e hpv em adolescentes. Escola Anna Nery Revista de Enfermagem, São Paulo, v. 14, n. 1, p. 126-34, jan./mar. 2010.

CRUZ, D. E.; JARDIM, D. P. Adolescência e Papanicolau: conhecimento e prática. Adolescência \& Saúde, Rio de Janeiro, v. 10, n. 1, p. 34-42, abr. 2013.

DUAILIBI, L. B.; RIBEIRO, M.; LARANJEIRA, R. Perfil dos usuários de cocaína e crack no Brasil. Cad. Saúde Pública [online], [S.L], v. 24, n. 4, p. 547-557, jan. 2008.

DUAVY L. M. et al. A percepção da mulher sobre o exame preventivo do câncer cérvicouterino: estudo de caso. Ciência \& Saúde Coletiva, Rio de Janeiro, v. 12, n. 3, p. 733-742, maio/jun. 2017.

FERREIRA, G. et al. Papilomavírus humano e a eficácia da vacina profilática para neoplasia intra epitelial cervical. SIMPÓSIO DE ASSISTÊNCIA FARMACÊUTICA, São Camilo, v. 1, n. 2, p. 1-3, maio 2015.

FRANCO, M. et al. Patologia: Processos Gerais. 6 ed. São Paulo: Atheneu. 2015. 338 p.

GONCALVES, H. et al. Determinantes sociais da iniciação sexual precoce na coorte de nascimentos de 1982 a 2004-5, Pelotas, RS. Rev. Saúde Pública, São Paulo, 2009. Disponível em http://www.scielo.br/scielo.php?script=sci_arttext\&pid=S003489102008000900006\&Ing=pt\&nrm=iso. Acesso em: 20 nov. 2019.

INCA. Instituto Nacional do Câncer. Tipos de câncer. Disponível em: http://www2.inca.gov.br/wps/wcm/connect/inca/portal/home. Acesso em: 28 fev. 2018. 
INSTITUTO NACIONAL DE CIÊNCIA E TECNOLOGIA DAS DOENÇAS DO

PAPILOMAVÍRUS HUMANO. Guia do HPV - entenda de vez os papilomavírus humanos, as doenças que causam e o que já possível fazer para evitá-los. São Paulo: jul. 2013. 41 p.

Disponível em:

http://www.incthpv.org.br/upl/fckuploads/file/guia\%20do\%20hpv\%20julho\%202013_2.pdf. Acesso em: 6 out. 2019.

INSTITUTO ONCOGUIA. Vacina HPV. 2014. Disponível em: http://www.oncoguia.org.br/conteudo/perguntas-e-respostas-sobre-a-vacina-profilaticacontra-o-hpv/2592/488/. Acesso em: 16 nov. 2018.

JARDIM, F. A. et al. Doenças Sexualmente transmissíveis: a percepção dos adolescentes de uma escola pública. Cogitare Enferm, v. 18, n. 4, p. 663-668, out./dez. 2013.

LETO, M. et al. Infecção pelo papilomavírus humano: etiopatogenia, biologia molecular e manifestações clínicas. Anais Brasileiros de Dermatologia, São Paulo, v. 86, n. 2, p. 306317, jul. 2011.

LIMA, P. V. C. et al. Saúde do adolescente - conceitos e percepções: revisão integrativa. Rev. enferm. UFPE on line, Recife, PE, v. 8, n. 1, p. 146-154, jan. 2014.

LUSTOSA, N. H. R. et al. Conhecimento e atitudes de adolescentes em relação à prevenção da infecção por HPV e sua correlação com o câncer de colo do útero. Temas em Saúde, João Pessoa, PB, v. 16, n. 3, p. 333-352, jan. 2016.

MACÊDO, F. L. D. S. et al. Infecção pelo HPV na adolescente. Feminina, Teresina, PI, v. 43, n. 4, jul./ago. 2015.

MARQUES, J. M.; RAMOS, E.S.F. Atuação do enfermeiro frente ao exame colpocitológico. Revista Educação, Meio Ambiente e Saúde, [S.L], v. 7, n. 2, abr./jun. 2017.

PAIVA, V. et al. Idade e uso de preservativo na iniciação sexual de adolescentes brasileiros. Revista de Saúde Pública, São Paulo, v. 42, supl.1, jun. 2008.

PIRES, M. M. et al. Reconstructing past ecological networks: the reconfiguration of seeddispersal interactions after megafaunal extinction. Oecologia, São Paulo, v. 175, n. 4, p. 1247-1256, maio 2014.

QUINTELLA; C. ZANON, C.M.A. A atuação da enfermagem: uma contribuição para prevenção do câncer ginecológico. Projeto de tese. Universidade Federal de Santa Catarina, Florianópolis, 2012.

RODRIGUES A.; SOUSA J. Papilomavírus humano: prevenção e diagnóstico. Revista de Epidemiologia e Controle de Infecção. São Paulo, v. 5, n. 4, p. 197-202, 2015.

SANTOS, N.; ROMANOS, M.; WIGG, M. Introdução à: Virologia Humana. 2 ed. Rio de Janeiro: Guanabara Koogan, 2008. 532 p.

SANTOS, T. M. B. D. et al. Fatores que contribuem para o início da atividade sexual em adolescentes: revisão integrativa. Rev. de Atenção à Saúde, Recife, PE, v. 13, n. 44, p. 64- 
70, jan. 2015.

SILVA, A. D. S. N. et al. Início da vida sexual em adolescentes escolares: um estudo transversal sobre comportamento sexual de risco em Abaetutuba, Estado do Pará, Brasil. Instituto de Ciências Biológicas, Belém, PA, ago./abr. 2015.

SILVA, G. R.; CRUZ, N. R. D.; COELHO, E. J. B. Perfil nutricional, consumo alimentar e prevalência de sintomas de anorexia e bulimia nervosa em adolescentes de uma escola da rede pública no município de Ipatinga, MG. Revista Digital de Nutrição, Ipatinga, MG, v. 2, n. 3, ago./dez. 2008.

TORRES, T. R. F. et al. O cuidado de enfermagem na saúde sexual e reprodutiva dos adolescentes. Revista oficial do núcleo de estudos da saúde do adolescente/UERJ, v. 10, Supl. 1, abr. 2013.

\section{Como referenciar este artigo}

COSTA, Daniel Aser Veloso; RIBEIRO, Tayanne Rodrigues. Vulnerabilidade de Jovens e Adolescentes à Infecção por HPV e as Condutas Preventivas da Enfermagem. Temas em Educ. e Saúde, Araraquara, v. 15, n. 2, p. 217-233, jul./dez. 2019. e-ISSN: 1982-5587. DOI: https://doi.org/10.26673/tes.v15i2.12776

Submetido em: 20/01/2019

Revisões requeridas: 30/03/2019

Aprovado em: 30/04/2019

Publicado em: 30/07/2019 